\title{
Stereotyping by Default in Media Transfer
}

\author{
Luc van Doorslaer
}

\begin{abstract}
This contribution looks at the added value that journalistic discourse and approaches from translation studies can offer to imagology. Translation studies nowadays is a discipline no longer dealing with interlingual transfer only, but also with intralingual as well as intercultural communication transfer and all changes involved in processes of rewriting and adaptation. A great deal of journalistic production is the result of such processes of rewriting and recontextualising. Journalistic translation research has paid attention to this by coining terms such as 'transediting' or 'journalator', indicating the overlap between the activities and the actors. Acts of recontextualising inevitably deal with the transfer of (national and cultural) images and stereotypes, as well as the conscious and unconscious changes involved. In modern media societies journalistic discourse is highly influential in producing and distributing national and cultural stereotyping. Under certain circumstances stereotyping is likely to function by default in journalism, the so called 'automaticity of stereotyping'. This phenomenon is illustrated with several examples from journalistic discourse. They are frequently found in sports journalism, but this contribution also offers examples from political journalism related to the presentation of Germany and Europe.
\end{abstract}

\section{Introduction}

One of the fascinating characteristics of imagology is its relative intangibility. Studying national and cultural images and ethnotypes could have the potential of being a discipline or subdiscipline. But as imagology lacks the necessary institutionalisation level, it cannot be considered a discipline or even subdiscipline. Sometimes it is called a "working method"1. However, I'm not aware of a general handbook of methodology specifically mentioning imagology. Though an imagological approach complies with the classical features of adopting a method (systematicity of investigation, a mode of procedure, etc.), it is never

1 Leerssen (2016), p. 19.

(C) LUC VAN DOORSLAER, 2021 | DOI:10.1163/9789004436107_012

This is an open access chapter distributed under the terms of the CC BY-NC-ND 4.0 license. 
put at a similar level with methods such as discourse analysis, corpus gathering, keystroke logging, eye tracking, interviews or surveys. Imagology rather functions as a selection principle, it is a lens through which the material is studied, a perspective functioning as a criterion for selecting the potentially relevant material. Such a lens can be adopted with the help of several methods. An imagological lens can be applied through text analysis or interviews, an imagologically based selection is possible with corpora or eye tracking. If imagology is considered this way, the relatively recent extension of imagology to other than literary discourse may be considered a natural development. ${ }^{2}$ More in particular, this contribution elaborates on the added value that materials and approaches from journalistic discourse and translation studies could offer to imagology. Such a possible input will be illustrated with several examples.

\section{The Potential Added Value of Journalism Studies}

It is obvious that the huge amount of research on representation in journalism studies and the study of stereotypes have certain aspects in common. ${ }^{3}$ On the other hand imagology's focus on the function of literary and cultural transfer in ethnotyping, in combination with its attention for diachrony, shows a much more specific object and approach. The origins of imagological research in literary studies have also contributed to an emphasis on the richness of literary discourse in this regard. Joep Leerssen has rightly stressed the importance of literary canonicity strengthening the perception of ethnotypes, thereby considering other text types, such as journalism, as "more ephemeral sources". ${ }^{4} \mathrm{On}$ the other hand, in our modern media world journalistic discourse is omnipresent. Despite its undeniably ephemeral character, the feature of constant repetition of certain (national and cultural) stereotypes in the media may achieve an effect similar to canonisation. Looking at it from this perspective, it might be worthwhile addressing the relative underrepresentation of journalistic discourse in imagology.

This underrepresentation is indeed relative, not absolute. Some studies have already shown the potential imagological relevance of journalistic sources. This is explicitly done by Corinne Fowler (2007) where she investigates the role of journalism in the development of British ideas about Afghanistan. The

\footnotetext{
2 For instance in van Doorslaer (2010) or van Doorslaer (2012).

3 One example explicitly connecting representation with discourses of identity and Self-Other rhetoric is Le (2006).

4 Leerssen (2007), p. 26.
} 
British news media coverage about the 2001 conflict relied on "heavily fictionalised and mythologised notions of Afghanistan". ${ }^{5}$ Interestingly, Fowler shows how the journalists copied - and as such also confirmed - centuries-old clichés that were transmitted through journalistic accounts and travel narratives.

Casting its net deep into the nineteenth century, the study investigates how British travellers and journalists continue to inherit the paranoias and prejudices of their nineteenth-century predecessors and why, in British imaginations, Afghans tend to remain warlike, medieval, murderous and unruly. ${ }^{6}$

It is no coincidence, particularly in historical research, that travellers and journalists are mentioned on equal footing. Travel writing and travel journalism form a productive mixed genre for clichés and national or cultural stereotyping, as they register otherness and explore "individual and national identity. [...] travel writing is almost invariably about Self and Other". ${ }^{7}$ Lily Coenen's study (2013) on the image of Spain in Dutch travel writing is an example showing the development and variety of such image-building over a century of time, and how the authors were intertextually influenced by the readings of literary fiction and figures functioning as "floating signifiers". ${ }^{8}$ Intertextuality is not only a feature of literary, but also of journalistic discourse. Discursive reflections of otherness, or at least the way otherness is perceived, is the heart of the matter of imagological research. Against this background it is also relevant that Coenen stresses the interdependency of hetero- and auto-images: the changes in the perception of Spain were often related to a projection need of the Dutch authors.

This reminded me of similarities with a research project on 'Literary Travel Journalism' I conducted with students of a Master's seminar at KU Leuven a few years ago. Though the results were never published because of the small scale of the project, they are interesting in this context. The students investigated contemporary travel journalism about South Africa in Dutch-language sources, both from the Netherlands and Belgium (Flanders). The 16 examples in the corpus were all longer texts with literary characteristics. The analysis of the varying foci and topics showed that there was a considerable difference between the approach of the articles published in the Netherlands and

\footnotetext{
5 Fowler (2007), p. 4.

6 Fowler (2007), p. 4f.

7 Coenen (2013), p. 8.

8 Coenen (2013), p. 177 .
} 
in Flanders. The Dutch authors made use of much less historical facts and focused on modern post-apartheid South Africa. The Flemish authors, on the other hand, used a much more historicising and contrastive approach, referring to racial, social, political and linguistic conflicts in the so called Rainbow nation - the term coined by the South-African Archbishop Desmond Tutu. A hypothesis for further research could be: even within the same Dutch-language area, the auto-image of the travel author is more determining for the approach of the object than the hetero-image. In this case it would mean that the Flemish authors, living in a country (Belgium) with a history (and sometimes present) of frequent political tensions due to language issues, tend to project these contrastive categories on the description and explanation of other countries as well. Whereas the Dutch authors, living in an officially monolingual country much less determined by language issues, adopt a less contrasting approach. Or in alternative imagological terms: the chosen perspectives may tell us more about the spectant (the author representing the represented) than about the spected, the represented country that is the actual object of the article.

Although imagology up to now has primarily studied literary representation, more journalistic types of discourse such as travel writing - "a type of text or genre that has received much more attention than earlier and has moved from the periphery much closer to the centre of current academic discourse" - enable and facilitate a media-oriented extension of the research object. ${ }^{9}$ This would also reflect the crucial role mass media in modern societies have in the expression of cultural identities: "it is uncontested that radio and television [...] have played a central role in the dissemination of national culture, national values and national stereotypes."10

Moreover, there are interesting interdisciplinary connections possible between imagology and some of the journalism studies research on representation and stereotyping. An example would be the research by Dominic Lasorsa and Jia Dai (2007) on (intentional or unintentional) default stereotyping as well as the "overabundance of nationality-related stereotypes" in the writing of deceptive news stories. ${ }^{11}$ According to their study, the less journalists are informed, the more they stereotype. Where gaps have to be filled in in journalistic production (a daily practice), it regularly happens that stereotypes are taken over from hear-say or from earlier news items.

9 Zacharasiewicz (2009), p. 26.

10 Göttlich (2007), p. 356.

11 Lasorsa, Dai (2007), p. 292. 
All these perspectives suggest that in the presence of a mass of potential facts, stereotyping tends to occur to streamline work and ease the perceiver's discrepancy between what is expected and observed. Unless a perceiver is able and motivated not to stereotype, stereotyping is likely to function by default, a process psychologists call automaticity.12

This phenomenon of the automaticity of stereotyping in journalism, as an element in the journalistic process of streamlining work and content in the chaos of facts, would deserve to be related to imagological insights such as the oppositionality of ethnotyping or the ways in which Self-Other oppositions are implied or invoked. ${ }^{13}$

One of the elements essentially linking up the previous examples from travel writing, literary travel journalism or the automaticity of stereotyping, is the determining position of the author. "One of the basic insights in image studies is that the mechanism of the representation of foreign nations can only be analysed properly if we take the attitude of the author into account."14 Besides the elements of cross-fertilisation between imagology and translation studies already dealt with elsewhere, ${ }^{15}$ such as the descriptive and diachronic viewpoints or the centrality of change and hybridity, indeed, also the role of the author in the discursive variation of representation is a fundamental common feature. A translator is undeniably a cultural mediator, "an informant who transfers cultural knowledge from a primary context to a secondary one"16 and who also authors a new text. The literary publishing world creates the illusion that we read Franz Kafka when we read 'The Castle' in English, but in reality 'The Castle' is a text of which Kafka has not written one single word, but is a re-creation of the English translator. The illusion is based on the obsolete model that languages are equivalent structures as well as on the romantic concepts of originality, the unique authority of the source text ('original') and the source text author.

\footnotetext{
12 Lasorsa, Dai (2007), p. 281. Italics in original article.

13 Compare for instance with Leerssen (2016), p. 17.

14 Leerssen (s.d.).

15 See van Doorslaer, Flynn, Leerssen (2015), pp. 2-4.

$16 \quad$ Keller (2007), p. 357.
} 
Journalistic translation research over the past two decades has been a case in point showing that such a model does not correspond to modern reality any longer - if it ever really has before. ${ }^{17}$ Not only are languages never equivalent structures, the daily practice of international journalism also illustrates both the ubiquity and the complexity of the multiplication of source texts and multi-authored journalistic texts. ${ }^{18}$ In such a complex writing and rewriting situation of text production, both intra- and interlingual, translation in the journalistic field not only disintegrates the status of the source text, it also problematizes the very concept of traditional authorship..$^{19}$ It is no coincidence that research on translation in journalism has led to the coinage of hybrid terms such as 'transediting' ${ }^{20}$ or 'journalator,'21 indicating the blurred borders between translating and (journalistic) authoring. In systemic terms, the rewriting, re-editing and recontextualising practices in journalism could be considered an example of "intrasystemic translations" within the journalistic system. ${ }^{22}$

Exactly this hybridity and complexity of the author status is also important from an imagological perspective with regard to the above mentioned attitude of the author. Interlingual translation, and even more so intralingual and intersemiotic translation, ${ }^{23}$ offers the author-translator an extra filter in the rewriting or re-conveying of images. When translation is no longer traditionally looked at in terms of non-change, but as an element in a chain of textual, contextual and intertextual change, it contributes to the diversification of stereotyping as well.

The non-change paradigm has therefore been subverted by recognising the impossibility of total invariance or full equivalence not only in translation practice, but also and above all in the scholarly study of translation. [...] Observations and descriptions of the reality of translation showed many practices and circumstances that were based on anything but non-change. The inevitability of translators' choices, cultural context, ideological influences, role of agency and idiosyncrasy, multilingual pro-

\footnotetext{
17 See the overview articles Valdeón (2015) and Davier, Schäffner, van Doorslaer (2018).

18 See for instance Schäffner (2012).

19 Van Doorslaer (2010), p. 181 .

$20 \quad$ In Stetting (1989).

21 In van Doorslaer (2012).

22 D'hulst (2008), p. 85.

23 Three types of translation already distinguished in Jakobson (1959).
} 
cessing in newsrooms, travel and migration as translational phenomena, transfer of national and cultural images through translation - these are all examples of situations where translation is fundamentally involved in a (much more than interlingual) process of change. As change inevitably puts more emphasis on contrasts and dissimilarities, elements of difference have complemented the traditional focus on sameness. ${ }^{24}$

An example of this potential power of translation for the distribution of images is the discussion in China about the 'correct' dissemination of Chinese culture through English translations, including the question whether this can be executed better by English native translators or by native Chinese. ${ }^{25}$ The attitude of the author-translator is the heart of the matter in this discussion. This Chinese case of auto-image-building illustrates the use of translation for selecting and highlighting certain features, a well-known principle in the rhetoric of ethnotyping with the help of certain "characteristics presented as being meaningfully representative of the nation". ${ }^{26}$ A notorious historical example illustrating the double-sidedness or power of translating mediators is that of La Malinche or Doña Marina, the (among other things) local interpreter of Spanish conquistador Hernán Cortés. ${ }^{27}$

\section{$4 \quad$ Journalistic Illustrations}

Case studies explicitly dealing with journalistic discourse in translation can be found in several chapters of Interconnecting Translation Studies and Imagology. ${ }^{28}$ Maria Cristina Caimotto studies news translation practices as well as projected self-images between the UK and Italy in the 1970s. ${ }^{29}$ Both Roberto Valdeón and Denise Filmer combine their analysis with the concept of framing. Valdeón's case shows the combination of more modern and more traditional, negativised images about Spain in El País English Edition. ${ }^{30}$ Filmer criticizes the British journalists for framing Italy through reinforced stereotypes of

\footnotetext{
24 Van Doorslaer (2018), p. 222.

25 See for instance $\mathrm{Hu}(2 \mathrm{O15})$.

26 Leerssen (2016), p. 17.

27 See for instance Keller (2007), p. $35^{8}$ or Valdeón (2013).

28 Van Doorslaer, Flynn, Leerssen (2015).

29 See Caimotto (2015).

30 See Valdeón $(2015 \mathrm{~b})$.
} 
former prime minister Silvio Berlusconi, using translation as "an ideological prop" to intensify certain news narratives. ${ }^{31}$

The fact that national categories are top-of-mind in journalistic categorisations, is nothing new in itself. Already Michael Billig extensively showed the ubiquity of "banal nationalism" in journalistic discourse. ${ }^{32}$ Not extreme, but daily signs of national identity are continuously "flagged in the media": ${ }^{33}$ in the use of flags, us and them discourse on national grounds, national museums, the weather forecast presented on national maps, etc. Within the journalism sections, a leading exponent of the continuation and confirmation of banal nationalism is sports journalism: "the sporting pages repeat the commonplace stereotypes of nation, place and race". ${ }^{34}$ An interesting study concentrating on exactly that topic, the national stereotyping in sports journalism, was conducted by Maarten van Bever. Despite being a Master's thesis, the investigation was very well focused and methodologically sound. Van Bever analysed three popular Dutch-language Belgian newspapers in the summer of 2008, particularly focusing on national stereotyping during the European Football Championship played in Austria and Switzerland. The three countries with the highest number of stereotypes were the Netherlands, Germany and Spain. Whereas the neighbouring fans of the Netherlands were often presented as partying, loud, self-confident, sometimes arrogant (all existing stereotypes about the Dutch in Belgium), even more interesting were the references used for describing the finalists Spain and Germany, supposedly the two best teams of the tournament. The representation of Spain stressed the technical aspects of their way of playing, the frivolous and tiki-taka features, but was also connected with emotionality as well as southern and relaxed characteristics. In the case of Germany however, several of the 81 stereotypes in the corpus referred to solidity, power, strength, Sturm und Drang, and no less than nine of them to a war context (e. g. Poland, nazis, Anschluss).

A more recent (unpublished) small-scale study has yielded similar results that can be related to national image-building. A Master student compared the use of typifying words of two teams that were coached by the Spanish-Catalan football coach Pep Guardiola. Although among football specialists it is generally accepted that the way of playing of both Barcelona and Bayern Munich in their Guardiola era was very similar, the corpus showed that terms such as 'machine' or 'bulldozer' were several times used for Bayern, but never for

\footnotetext{
$31 \quad$ Filmer (2015), p. 272.

$32 \quad$ See Billig (1995).

33 Billig (1995), p. 119.

34 Billig (1995), p. 120.
} 


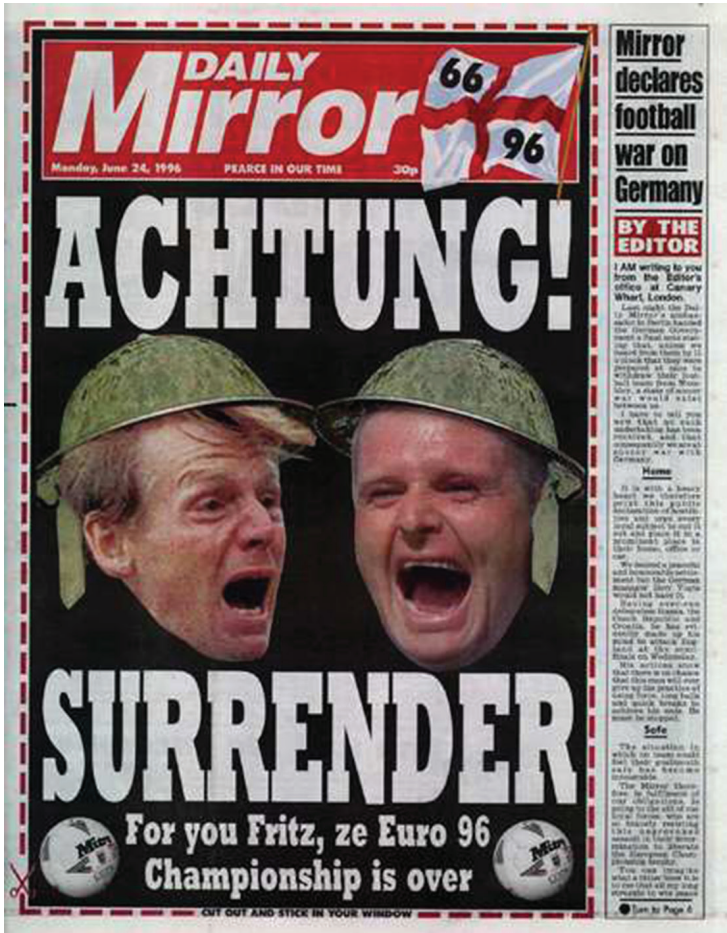

FIGURE 10.1

Front page of the Daily Mirror, 24 June 1996

Barcelona. Lasorsa and Dai's automaticity of stereotyping seems to be omnipresent in sports journalism.

The fact that Germany is an interesting example for imagological research, is in itself not new. Several chapters in Imagology Revisited thematised the image of Germany in America from a historical perspective, for instance. ${ }^{35}$ But the combination of popular press and sports has the potential to intensify and magnify simple images. Well-known was also the Euro 1996 organised in and by England, especially the semi-final between England and Germany. The coverage of that match has been described "as the lowest point in British press coverage of football" 36 . The most famous and extensively discussed front page was that of the Daily Mirror (see fig. 10.1), featuring two English players wearing helmets and the editor declaring the football war on Germany. Despite the newspaper announcing that the Euro 96 would be over for 'Fritz', two days later Germany eliminated England and went on to the final to become the European champions.

35 See Zacharasiewicz (2010).

$36 \quad$ Mark Christopher Watkin, cited in Belam (2008). 
Such "patriotic frenzy" over sports topics can become constitutive for the intensification and automaticity of stereotyping through the media. ${ }^{37}$ "A nation's image, usually constructed in great part by and through the media, can become, over time, part of a national political culture."38 Also Jonathan Grix and Chantal Lacroix (2006) have worked on the case of Germany and the way its image was (re)constructed by the British press after the Second World War. Although they distinguish eight different stereotypes, the one that is by far outnumbering all others is the war-related stereotype. Despite the ephemeral feature of media discourse, its massive presence as well as the repetitive character of the stereotypes can be very powerful in the distribution of clichés.

It is thus clear that the media plays a major role in shaping UK citizens' image of Germany. The school curriculum does not appear to have enough space and time to counter-balance the avalanche of stereotypical coverage of Germany and Germans on television or in the print media. Thus, the outmoded image of Germany presented in the media goes unchecked by any other source that may allow people the chance to correct or adjust their perception of Germany and Germans. ${ }^{39}$

This example illustrates again that the constant repetition of stereotypes is the media's effective weapon that compensates its ephemerality and leads to effects that can be considered similar to canonicity. On top of that, because of the fast production and rapid distribution features of modern online and social media, the repetition is even multiplied.

Although sports coverage may intensify nationalistic and stereotyping tendencies, it is certainly not the only media section making use of the strong emotional potential of simplified national images. Related to the focus on Germany in this part would be examples of political media coverage such as the financial crisis in Greece or the political clashes between the Turkish Erdoğan regime and several Western European countries. In line with the football war references in the British tabloids, the reduction of Germany's past to the nazi regime was frequently employed in the Greek and Turkish media. This is illustrated in fig. 10.2, dating from 2017, when Germany was harshly criticised in the Turkish press because of the cancellation of Turkish ministers' election rallies in Germany.

\footnotetext{
$37 \quad$ Belam (2008).

38 Grix, Lacroix (20o6), p. 373.

39 Grix, Lacroix (2006), p. 388.
} 


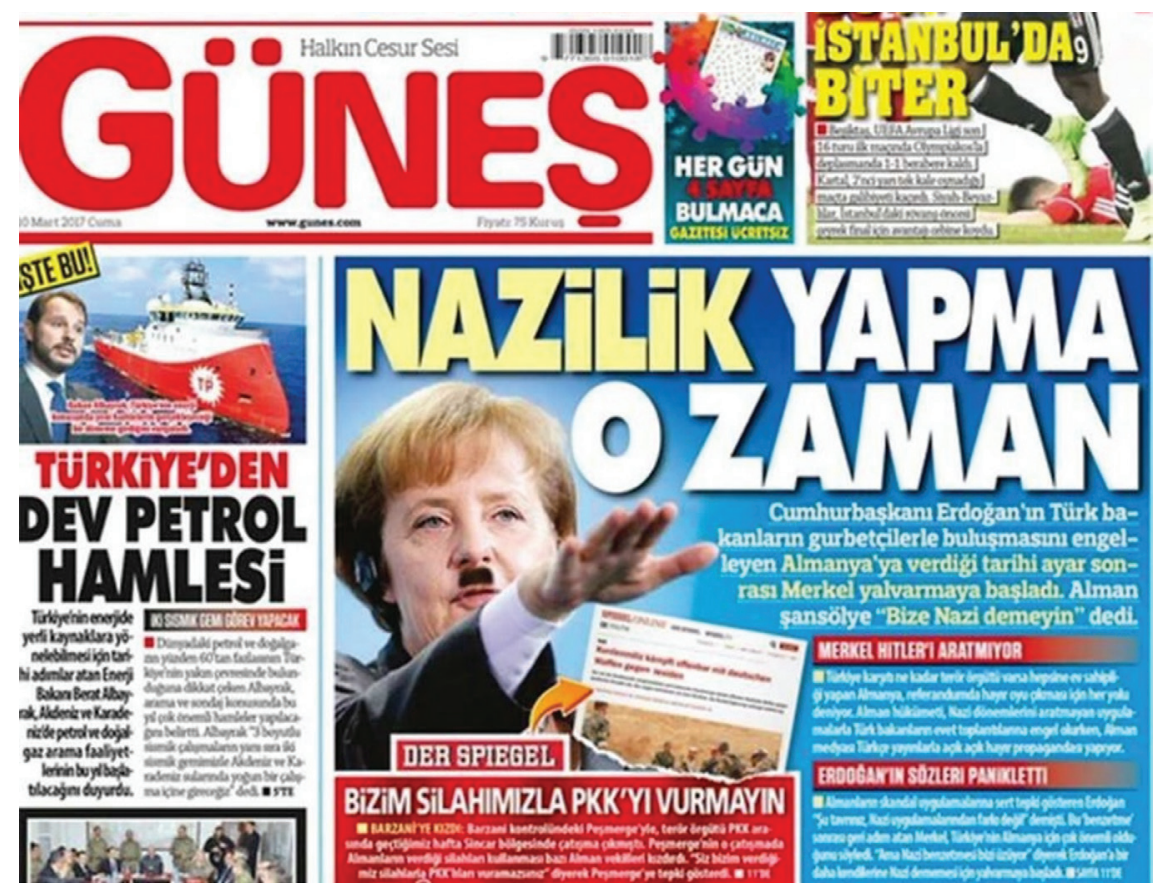

FIGURE 10.2 German Chancellor Angela Merkel presented as Hitler in the Turkish newspaper Güneş

Journalistic discourse is a rewarding object of research for imagology, since some journalistic practices reinforce one-sidedness as an element of the automaticity of stereotyping. The representation of Germany (or Germans) is a case in point. Out of the range of historically available national images, in European media it is for instance not the (eighteenth and nineteenth-century) land of poets and philosophers that is referred to. In topics with an economic or financial content, the industrial or technological power is often stressed, dating back to the end of the nineteenth century, the German Gründerzeit. But by far the most frequently used image relates to the period of the two world wars and the nazi regime in the 1930 and 40 . The reduction is obvious in temporal terms, as this period (if one includes WW I) covers less than three decades in a centuries-old history. Historical reduction and one-sidedness in image-building go hand in hand.

The effect of repetition in journalism is also reinforced by the use of dichotomous categories. An oppositional, occasionally black and white presentation belongs to the toolbox of every communicator who has to present a complex situation to a larger audience. But if such a simplified presentation is successful, it can become ingrained and difficult to correct at a later stage. An example is the 


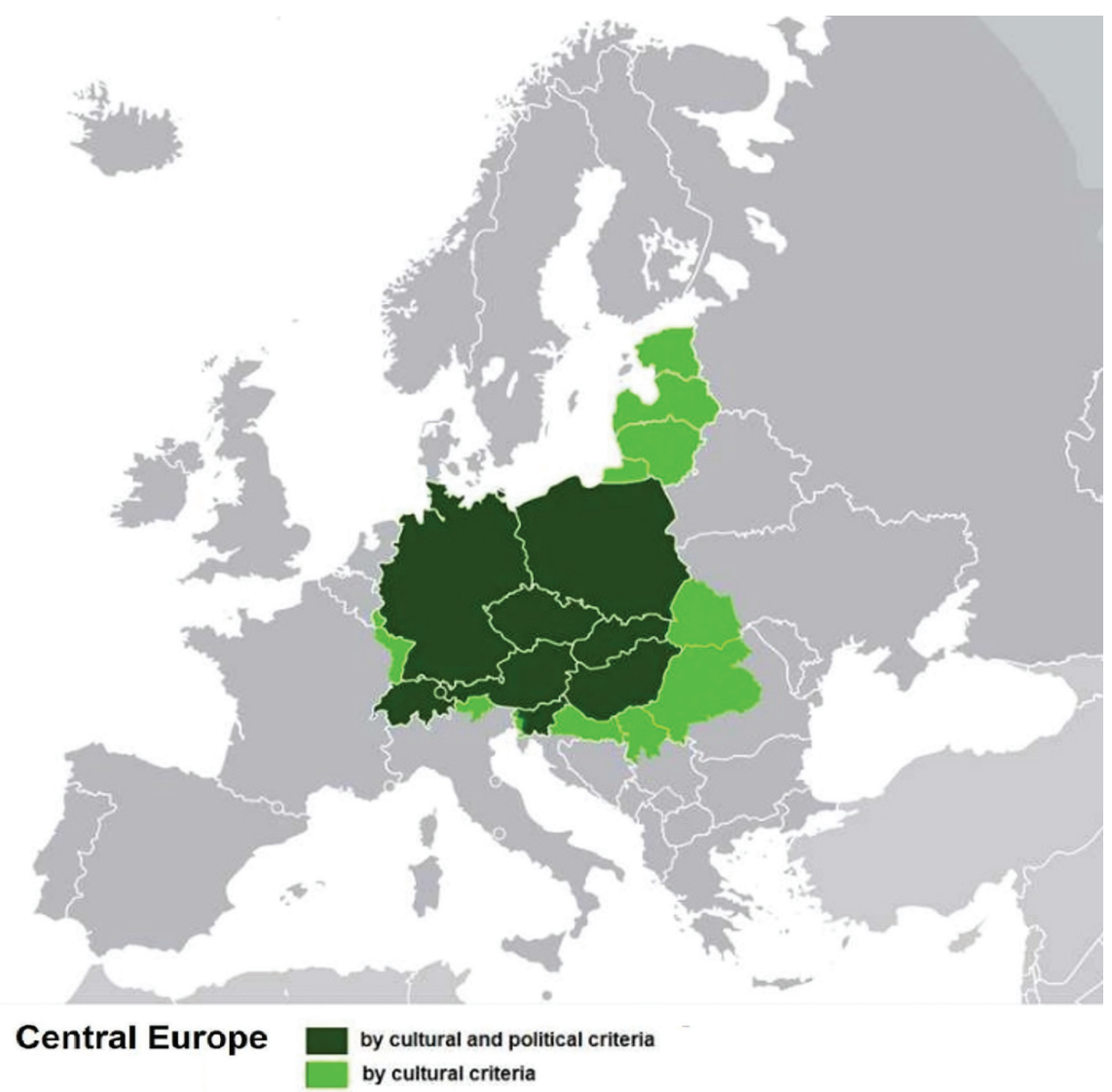

FIGURE 10.3 Central Europe by political as well as cultural criteria

division of Europe in two categories: Eastern vs. Western Europe, referring to the Cold War era and the Iron Curtain. It is a distinction that is frequently, almost automatically made in journalistic discourse. This is remarkable, taking into consideration that the Iron Curtain does not exist anymore for more than thirty years. Nevertheless it still seems to be the determining element for a simplified division of the European continent, including the connotations of East and West that also refer to Cold War commonplaces. A more nuanced, trans-dichotomous, but also fuzzier concept such as 'Central Europe' is hardly used. Central Europe does not have clear borders marked by an Iron Curtain, but is a term with a combination of historical, cultural and political content. A map illustrating this poly-interpretability is included in the Wikipedia page about Central Europe, referring to the Leibniz Institute for Regional Geography as its source. ${ }^{40}$

40 Two emails sent to the Leibniz Institute for Regional Geography asking for more information about the map remained unanswered. 
Whereas political criteria would place Central Europe perfectly within the present political borders of Austria, the Czech Republic, Germany, Hungary, Poland, Slovakia, Slovenia and Switzerland, cultural and historical criteria also include parts of several other countries, taking into account that these regions were part of the former German empire, the Austro-Hungarian monarchy or the Polish-Lithuanian Commonwealth. Just like the Iron Curtain, these are historical situations that are no longer valid. It is mainly the fuzziness of the borders that makes the concept of Central Europe much less attractive for journalistic use than the bi-polarity of Eastern vs. Western Europe.

The choice for a specific presentation or framing is immediately related to the auto-image of Europe, a topic that was mainly elaborated in a Dutchlanguage book by Leerssen (2011). The oppositional pattern of Eastern vs. Western Europe relies on a relatively limited period during the twentieth century on which basis European ethnotypes are constructed: "Eastern locations are often linked to despotic regimes, western ones to democratic values." ${ }^{41} \mathrm{~A}$ counterforce to the East-West dichotomous presentation is for instance the Visegrád group, founded in 1991. It is a cultural and political alliance between the Czech Republic, Hungary, Poland and Slovakia. Its name is based on historical and cultural grounds, referring to a congress in the Middle Ages in the same location. Interestingly this collaboration starts from an idea of strength and collaboration of Central European states, which theoretically would have the potential of replacing an East-West narrative by a Centre-Periphery narrative. At the beginning of 2018, the new conservative government of Austria explicitly mentioned the wish to collaborate more intensely with the Visegrád countries. Although this was mainly based on common ideas about migration policy, at the same time it was a symbolic challenge of the still dominant Iron Curtain division: a 'western' country showing its preference for collaboration with 'eastern' partners. A nineteenth and twentieth century-based cultural and political reality of Austro-Hungarian collaboration pushed aside the more recent Cold War division, with both of those periods having resorted to instances of ethnotyping.

Despite the stereotypical potential of bordering based on wind directions, the arbitrariness of such separations is also shown by other examples. In the north of Europe, the term 'Central Europe' is often used as part of a northsouth presentation, meaning the central part between north and south. And the Baltic Sea is called 'Ostsee' [Eastern Sea] in German, but 'Läänemeri' [Western Sea] in Estonian. Assigning intra-European ethnotypical characteristics becomes almost a haphazard exercise in such cases. 


\section{Conclusions}

Imagological research may sometimes be criticised for focusing on national or cultural essentialisms. Recently Leerssen ${ }^{42}$ has convincingly demonstrated why such views are misguiding. ${ }^{43}$ Although the nation-state is no longer a selfevident category in many scholarly disciplines, national and cultural ethnotyping are ubiquitous in other types of discourse. We have seen that in journalism, stereotyping can be an automaticity. National boundaries are sometimes used as tools to explain or demarcate phenomena that are older and more complex. The border between the Netherlands and Belgium, for instance, is often described in the press as not only a state, but also a religious frontier: the protestant North (the Netherlands) vs. the catholic South (Belgium). On this basis, ethnotypical differences of mentality between the Dutch and the Belgians are constructed and reinforced. But the state border between the two countries has never been the religious boundary. Approximately the south-eastern third of the Netherlands for centuries has been predominantly catholic, just like Belgium. It shows that national - or in this case state - borders are erroneously used as explanatory categories for phenomena that are older than the boundaries themselves.

The dominance of national categorisation for research, particularly for the selection of units of analysis or comparison, has been problematised in several scholarly disciplines. ${ }^{44}$ However, in journalistic discourse the predominance of national units of analysis can become a default stereotyping practice when used for explanatory or structuring purposes. Every transfer of information necessarily involves changes. That is the point where translation studies (studying both intra- and interlingual translation) shows an added value for imagological approaches. Journalistic text production is often a form of selecting, deselecting, re-editing and rewriting. These are already filters in an intralingual setting, but even more so when interlingual transfer is added. Every translator, journalist or narrator has to select and de-select when transferring and recontextualising information, including information about national and cultural images. This gatekeeping function inevitably generates interesting material for an imagological approach.

\footnotetext{
42 Leerssen (2016), p. $28 \mathrm{f}$.

43 Leerssen (2016), p. 28 f.

44 See van Doorslaer (2017), p. $220 f$.
} 


\section{Bibliography}

Belam, Martin (2008). “Achtung! Surrender" from The Mirror - Get your Euro 96 newspaper xenophobia here'. http://www.currybet.net/cbet_blog/2008/o2/achtung-surb render-from-the-mir.php [accessed 24.08.2018].

Billig, Michael (1995). Banal Nationalism (London: Sage).

Caimotto, M. Cristina (2015). 'Images of turmoil. Italy portrayed in Britain and re-portrayed in Italy', in Luc van Doorslaer, Peter Flynn, Joep Leerssen (eds), Interconnecting Translation Studies and Imagology (Amsterdam, Philadelphia: Benjamins), pp. 239-256.

Coenen, Lily (2013). The Image of Spain in Dutch Travel Writing (1860-1960). (Ph.D. Thesis: University of Amsterdam).

Davier, Lucile, Christina Schäffner, Luc van Doorslaer (2018). 'The Methodological Remainder in News Translation Research. Outlining the Background', Across Languages and Cultures, 19.2, pp. 55-64.

D'hulst, Lieven (2008). 'Translation and Its Role in European Literatures. Some Questions and Answers', in Nele Bemong, Mirjam Truwant, Pieter Vermeulen (eds), Re-Thinking Europe. Literature and (Trans)National Identity (Amsterdam, New York: Rodopi), pp. 81-91.

Filmer, Denise (2015). 'Images of Italy. The Words Berlusconi never (officially) said', in Luc van Doorslaer, Peter Flynn, Joep Leerssen (eds), Interconnecting Translation Studies and Imagology (Amsterdam, Philadelphia: Benjamins), pp. 257-276.

Fowler, Corinne (2007). Chasing Tales. Travel Writing, Journalism and the History of British Ideas about Afghanistan (Amsterdam, New York: Rodopi).

Göttlich, Udo (2007). 'Mass Media', in Manfred Beller, Joep Leerssen (eds), Imagology. The cultural construction and literary representation of national characters (Amsterdam, New York: Rodopi), pp. 354-357.

Grix, Jonathan, Chantal Lacroix (2006). 'Constructing Germany's Image in the British Press. An Empirical Analysis of Stereotypical Reporting on Germany', Journal of Contemporary European Studies, 14.3, pp. 373-392.

$\mathrm{Hu}$, Dexiang (2015). 'Translation into Other Languages as a Cultural Disseminator in China', Translation Review, 91, pp. 54-61.

Jakobson, Roman (1959). 'On linguistic aspects of translation', in Reuben Arthur Brower (ed.), On Translation (Cambridge: Harvard University Press), pp. 144-151.

Keller, Thomas (2007). 'Mediator', in Manfred Beller, Joep Leerssen (eds), Imagology. The cultural construction and literary representation of national characters (Amsterdam, New York: Rodopi), pp. 357-359.

Lasorsa, Dominic, Jia Dai (2007). 'When News Reporters Deceive. The Production of Stereotypes', Journalism \& Mass Communication Quarterly, 84.2, pp. 281-298.

Le, Elisabeth (2006). The Spiral of 'Anti-Other Rhetoric'. Discourses of Identity and the International Media Echo (Amsterdam, Philadelphia: Benjamins). 
Leerssen, Joep (2007). 'Imagology: History and Method', in Manfred Beller, Joep Leerssen (eds), Imagology. The cultural construction and literary representation of national characters (Amsterdam, New York: Rodopi), pp. 17-32.

Leerssen, Joep (2011). Spiegelpaleis Europa (Nijmegen: Vantilt).

Leerssen, Joep (2016). 'Imagology. On Using Ethnicity to Make Sense of the World', Iberic@l. Revue d'études ibériques et ibéro-américaines, 10, pp.13-31.

Leerssen, Joep (s.d.). 'A Summary of Imagological Theory'. http://imagologica.eu/theoS reticalsummary [accessed 14.08.2018].

Stetting, Karen (1989). 'Transediting. A new term for coping with the grey area between editing and translating', in Graham Caie et al. (eds), Proceedings from the Fourth Nordic Conference for English Studies (Copenhagen: University of Copenhagen), pp. 371-382.

Valdeón, Roberto A. (2013). 'Doña Marina/La Malinche. A historiographical approach to the interpreter/traitor', Target, 25.2, pp. 157-179.

Valdeón, Roberto A. (2015a). 'Fifteen years of journalistic translation research and more', Perspectives, 23.4, pp. 634-662.

Valdeón, Roberto A. (2015b). 'The construction of national images through news translation. Self-framing in El Pais English Edition', in Luc van Doorslaer, Peter Flynn, Joep Leerssen (eds) (2015). Interconnecting Translation Studies and Imagology (Amsterdam, Philadelphia: Benjamins), pp. 219-238.

Van Bever, Maarten (2011). Nationale beeldvorming in de sportjournalistiek. (MA Thesis: Lessius Antwerp).

Van Doorslaer, Luc (2010). 'The Double Extension of Translation in the Journalistic Field', Across Languages and Cultures, 11.2, pp. 175-188.

Van Doorslaer, Luc (2012). 'Translating, Narrating and Constructing Images in Journalism. With a Test Case on Representation in Flemish TV News', Meta. Translators' Journal, 57.4, pp. 1046-1059.

Van Doorslaer, Luc (2017). 'The Relative Need for Comparative Translation Studies', Translation and Interpreting Studies, 12.2, pp. 213-23o.

Van Doorslaer, Luc (2018). 'Bound to Expand. The Paradigm of Change in Translation Studies', in Helle V. Dam, Matilde Nisbeth Brøgger, Karen Korning Zethsen (eds), Moving Boundaries in Translation Studies (London, New York: Routledge), pp. 220-23o.

Van Doorslaer, Luc, Peter Flynn, Joep Leerssen (eds) (2015). Interconnecting Translation Studies and Imagology (Amsterdam, Philadelphia: Benjamins).

Zacharasiewicz, Waldemar (2009). 'The Theory of Climate and the North in Anglophone Literatures', in Sverrir Jakobsson (ed.), Images of the North: Histories - Identities - Ideas (Amsterdam, New York: Rodopi), pp. 25-49.

Zacharasiewicz, Waldemar (2010). Imagology Revisited (Amsterdam, New York: Rodopi). 